\title{
Activity of alpha amylase in tracheobronchial secretions of patients without morbid salivary aspiration
}

\begin{abstract}
Background: The normal value of alpha-amylase in humans is unknown.

Objective: To determine the normal values of alpha-amylase activity in humans.

Material and methods: From October 2009 to June 2011 we studied 111 patients referenced to thoracic service to be submitted to bronchoscopy. The patients were positioned in supine position, performed local antisepsis and anesthetized with $2 \%$ lidocaine. Thereafter we introduced a needle into catheter by puncturing the cricothyroid membrane using a $14 \mathrm{G}$ cateter. Finally we introduced ten milliliters of saline and immediately aspirated with the maximum power of the vacuum system. The samples were sent for $\alpha$ - amylase activity determination by CNPG method.
\end{abstract}

Results: The activity of $\alpha$-amylase of tracheal aspirate ranged from 24 to $10.000 \mathrm{IU} / 1$ ), and a mean 1914IU/L. The levels had no statistical differences according age, sex, race, smoking history and the lung diseases.

Conclusion: we could define the probably physiologic levels of amylase activity in humans beings.

Keywords: $\alpha$-amilase, lung, salivary aspiration, aspiration pneumonia, transtracheal puncture
Volume I Issue 3 - 2017

\author{
EP Almeida \\ Department of Surgery, Federal University of Juiz de Fora, Brazil
}

Correspondence: EP Almeida, Department of Surgery, Federal University of Juiz de Fora, MG, Brazil,

Email edmilton@terra.com.br

Received: June 07, 2017 | Published: July 03, 2017
Abbreviations: TTP, transtracheal puncture; TCP, transcrycoid puncture; NS, normal saline; SEM, standard error mean; UFJF, federal university of juiz de fora- minas Gerais-Brazil; UFMG, federal university of minas Gerais- Belo Horizonte- Brazil

\section{Introduction}

There is no reference in previously published material on the normal value of $\alpha$-amylase in tracheobronchial secretions. The amylase in the lungs of humans under normal conditions probably has two components-one is from local production and the other from physiological micro aspiration. ${ }^{1-6}$ Takano in 1938 demonstrated in rabbits that the blood of theirs right heart had major amylase concentration than the left chambers, which the plausible explanation is the passage of amylase from lung circulation to general circulation. Sano studying activity of enzymes in lung tissue of humans by hystochemical techniques found that the enzyme most frequently present on his specimens was amylase, principally of salivary type and discovered salivary glands acinus in lung parenchyma. ${ }^{2}$ In 1985 Nandapalan studying $\alpha$-amylase activity in laryngectomized patients without salivary fistula found a $\alpha$-amylase activity range from 35 to 1025 , mean 428, standard ad deviation 367 , and median of $295 \mathrm{IU} / \mathrm{l}$ in tracheobronchial secretions ${ }^{3}$. His group considered these values as the normal levels of this enzyme in normal human beings. We disagree with that conclusion because it has long being demonstrated that normal people microaspirate saliva. ${ }^{7-13}$ This is the main reason of our work, to define the normal levels of this enzyme in tracheobronchial secretions of people with very low possibility of morbid aspiration, based on known risk factors. There is a possibility that $\alpha$-amylase could be a marker of tracheobronchial aspiration of saliva and may be considered a tool for assessing aspiration of patients with oropharyngeal dysphagia. ${ }^{7-11}$ The main application of this tool could be in weaning from mechanical ventilation, allowing us to diagnose neurogenic dysphagia with major accuracy than the card test. Which is very subjective and as rule not used in clinical paractice. Currently, an objective tool to diagnose oropharyngeal dysphagia before extubation does not exist. By comparing saliva and tracheobronchial amylase activity, it is possible to diagnose oropharyngeal dysphagia and take measures to reduce saliva secretion and prevent weaning failure, thereby reducing morbidity, costs and mortality. This project was approved by CEP_HU_UFJF, Number: 0129/2009.The ideal procedure to define the physiologic parameters of lung amylase should use healthy volunteers ; but this probable would not be approved by the Committee on ethics in human beings, because the procedures have some side effects and a little, but possible, risk of complications.

\section{Objective}

To determine the normal levels of $\alpha$-amylase in tracheobronchial secretions and saliva of patients without risk of aspiration.

\section{Material and methods}

From October 2009 to June 2011, we prospectively evaluated 111 patients without clinical signals of hypersecretion who underwent transtracheal puncture before undergoing bronchoscopy. The study project was approved by the Ethics and Research Commission at the 
Juiz de Fora Federal University (number: 0129/2009), Minas Gerais, Brazil. All patients signed an informed consent term. Inclusion criteria were patients without hyper secretion in the tracheobronchial tree, and who were referred to the Thoracic Surgery Service for diagnostic flexible bronchoscopy. Patients with any risk factors for aspiration owing to neurologic or muscle degenerative disease, acute cerebral ischemic event, and surgery or radiotherapy of the cervical region, age higher than 65 years was not included in this study.

All patients were asked to lie in a supine position with light cervical hyperextension. The antisepsis was performed at the anterior cervical region using a 70\% alcoholic solution. All patients underwent sedation and local anesthesia. Anesthesia was administered intravenously with a combination of diazepam and meperidine to achieve a sedation level of 2-3 in the Ramsay scale. The local anesthesia comprised the skin, subcutaneous, and cricothyroid membrane levels and was performed using 0.5 to $1 \mathrm{ml}$ of $2 \%$ lidocaine solution $\left(\right.$ Xylestesin $\left.{ }^{\mathrm{R}}\right)$

We performed the puncture of the cricothyroid membrane with a $25 / 7 \mathrm{G}$ needle, and $10 \mathrm{ml}$ of lidocaine $(2 \%)$ without a vasoconstrictor was injected into the tracheobronchial tree. Lidocaine was allowed to take effect by waiting for 2 minutes and spreading into the tracheobronchial tree. This technique of anesthesia eliminates the cough reflex and leaves no free lidocaine in the major airways. The transtracheal puncture was then performed using an intravenous catheter passing into a $14 \mathrm{G}$ needle (BioCat ${ }^{\mathrm{R}}$-são Paulo-Brazil)..$^{7-13}$ After the puncture, the needle was positioned about $45^{\circ}$ in the cranial-caudal direction. With the catheter introduced $5-10 \mathrm{~cm}$ in the tracheal lumen, we performed an aspiration with the vacuum system at maximum power. In the event of no recurrence of secretion, the patient was confirmed as non-hypersecretory. For such cases, we proceeded with the infusion of $10 \mathrm{ml}$ saline solution, and immediately the catheter was connected to the vacuum system, through which the specimen was aspirated.The vacuum system was a conventional system with a pressure from 30 to $-40 \mathrm{~cm} \mathrm{Hg}$. When the volume of the aspirate was at least $100 \mu 1$, it was collected as a sample of saliva (bottle 1) and the aspirate (bottle 2).

The high viscosity of both fluids was responsible for the negative results in 19 patients. After diluting the samples, this problem was solved. After these procedures the patients were submitted to videonaso-laringo-bronchoscopy and evaluated for morbid aspiration. In case of positivity for aspiration the patient should be excluded from the study. This fact never had occurred. Activity of $\alpha$-amylase was measured using $\alpha$-2-chloro-p-nitrophenyl- $\alpha$-maltotrioside1,4 which is hydrolised by $\alpha$-amylase releasing 2-chloro $\mathrm{p}$ nitrophenol that can measured by photometry. We used LabMax240 (Labtest ${ }^{\circledR}$ - Amylase CNPG liquiform, Lagoa Santa, Minas Gerais, Brazil) for measuring of $\alpha$-amylase in both sample fluids. SPSS software version 13 for Windows was used to compile the survey data. We used, KS text for normality evaluation, $\chi$-squared test for categorical variables, Student $\mathrm{T}$ test for means and normal distributed, Pearson correlation for analyzing the relationship between salivary and tracheobronchial amylase, descriptive statistics and Kruskal-Wallis test to compare amylase activity among the various radiological diagnose .

\section{Results}

The population studied had a mean age of 48.7 years (standard deviation of 14.7 years), 77 male $77(77 \%), 72(65 \%)$ white and active smoking. There were no statistically significant differences in age, gender, race or smoking history (Table $1 \&$ Table 2).
Table I Main patient's characteristics

\begin{tabular}{lllll}
\hline & & $\begin{array}{l}\text { Number } \\
\text { of patients } \\
\text { percentage (\%) }\end{array}$ & Mean(age) & P value \\
Race & White & $72(65 \%)$ & 0.159 \\
Sex & Missing & $6(5 \%)$ & 0.139 \\
& Male & $77(70 \%)$ & \\
Smoking & Female & $34(30 \%)$ & 0.222 \\
& Nos & $7(68.5 \%)$ & 14.4
\end{tabular}

Table 2 Alpha amylase activity

\begin{tabular}{lll}
\hline Mean & Median & SEM \\
\hline $19141 \mathrm{U} / \mathrm{ml}$ & $10561 \mathrm{U} / \mathrm{ml}$ & $2401 \mathrm{U} / \mathrm{ml}$ \\
\hline
\end{tabular}

SEM, Standard error mean

\section{Discussion}

The $\alpha$-amylase activity in the human tracheobronchial tree seems to have two origins. One is from local production and the other is from physiological microaspiration. ${ }^{3-6}$ Nandapalan in 1995 published two works on this-one on laryngectomized patients and the other on tracheotomized patients. It was shown that the human lung produces amylases and thought that this should be the normal value of $\alpha$-amylase activity in humans. ${ }^{3}$ We disagree with this information because we have shown that physiological microaspiration occurs. ${ }^{4-6}$ Therefore, evaluating patients without the signs of morbid aspiration to obtain normal values of $\alpha$-amylase in the lungs needs to be performed. This is important because $\alpha$-amylase could be a useful tool in the diagnosis of morbid aspiration. ${ }^{7-13}$ The gold standard for diagnosis aspirations are videofluoroscopy and videoendoscopy. ${ }^{10}$ However, both methods have limitations. Videofluoroscopy is only useful in patients with some degree of cognition to obey the order made by the speech therapy specialist for treating oropharyngeal dysphagia. Videoendoscopy has advantages and disadvantages in comparison with videofluoroscopy; ${ }^{10}$ for example, videoendoscopy does not evaluate the oral phase of dysphagia, and, akin to videofluoroscopy, is not worldwide economically viable.Transtracheal aspiration or puncture (TTA, TTP) has been used widely because of the original publication, although it is not an ideal procedure because transfixing the anterior wall of the trachea, as in the original method carries major risk of haemorragic complications. ${ }^{7-13}$ The recommended name for this technique would be, "transcricothyroid membranes puncture" owing the fact it is an avascularity structure and with less chance of thyroid gland penetration, therefore with less chance of bleeding. ${ }^{11-13}$. The more appropriate term for the technique should be, "transcrycoid puncture (TCP)." However, the descriptor "transcrycoid" does not exist, and all the research on the current subject must use the terms "transtracheal aspiration and puncture." It is worth noting that our pilot study of 33 patients was critical in modifying the classical 
technique, which had been used exclusively for patients showing large levels of tracheobronchial secretions. Under such conditions, acquiring secretion samples by transtracheal puncture, with or without anesthesia of the tracheobronchial tree or intravenous sedation, is technically easier due to the fact that patients studied had hyper secretions and owing to bad healthy conditions were with reduced or nonexistent airway reflexes..$^{7-12}$ The current study differs from the previously published ones in various aspects. First, the sample population is inherently unique compared to that used previously, wherein all patients showed large amount of tracheobronchial secretions, and many of them were in poor health state. By contrast, patients of this study mostly were outpatients with good cognition and without any tracheobronchial hypersecretion. Second, a sedation protocol with the intention of obtaining 2-3 levels in the Ramsay sedation scale was used. In this situation, patients remain conscious and cooperative. In the present study it was observed that the range of variation of $\alpha$-amylase in the tracheobronchial tree, using $10 \mathrm{ml}$ of saline and transtracheal puncture was 24-10,000 IU/L (mean 1,914 IU/1; standard error mean, $240 \mathrm{IU} / 1$.). The inference of de double origin of $\alpha$-amylase in tracheobroncheal secretions is intuitive because the values in laryngectomized patients is very different from our population without risk of morbid aspiration and with normal airways anatomy and confirmed such data by naso videolaryngobronchoscop. ${ }^{10}$ The differences between our and Nandapalan's findings are due the target population studied. Nandapalan's study was carried out in tracheostomized patients without fistula, so They had laryngotracheal separation. In the present study there was a contribution of a physiologic micro aspiration that occurs in most normal people. Our work has many limitations, such as the sample size and being a single center study. We hope that other researchers could confirm or not our data and solve this controversial issue.

\section{Conclusions}

We have defined the normal values of amylase in tracheobronchial secretions of human beings. The $\alpha$-amylase in the human lung has probably two components: one produced locally and the other due to normal physiologically aspiration.

\section{Acknowledgements}

None.

\section{Conflict of interest}

The author declares no conflict of interest.

\section{References}

1. Nandapalan V, McIlwain JC, England J. Amylase activity in tracheobronchial secretions of laryngectomized patients. J Laryngol Oto. 1995;109(7):637-639.

2. Sano M, Zennami S, Masaoka A. Activities of some enzymes in tracheal and bronchial fluid. Panminerva Med. 1986;28(2):137-142.

3. Jr AJ. Aspiration bronchopneumonia. Int Anesthesiol Clin. 1937;3:126126.

4. Huxley EJ, Viroslav J, Gray WR, et al. Pharyngeal aspiration in normal adults and patients with depressed consciousness. Am J Med. 1978;64(4):564-568.

5. Gleeson K, Eggli DF, Maxwell SL. Quantitative aspiration during sleep in normal subjects. Chest. 1997;111(5):1266-1272.

6. Clarke PD, Bain BC, Davies A, et al. Aspiration in seriously ill patients: a study of amylase in bronchial secretions. J Clin Pathol. 1981;34(7):803805 .

7. Pecora DV. A method of securing uncontaminated tracheal secretions for bacterial examination. J Thorac Surg. 1959;37(5):653-654.

8. Morishita $\mathrm{Y}$, Iinuma $\mathrm{Y}$, Nakashima $\mathrm{N}$, et al. Total and pancreatic amylase measured with 2-chloro-4-nitrophenyl-4-O-beta-Dgalactopyranosylmaltoside. Clin Chem. 2000;46(7):928-933.

9. Nandapalan V, McIlwain JC, Hamilton J. A study of alpha-amylase activity in tracheobronchial secretions of seriously ill patients with tracheostomies. J Laryngol Otol. 1995;109(7):640-643.

10. Logemann JA, Rademaker AW, Pauloski BR, et al. Normal swallowing physiology as viewed by videofluoroscopy and videoendoscopy. Folia Phoniatr Logop. 1998;50(6):311-319.

11. Pecora DV. Transtracheal aspiration. American family physician/GP. 1970;1(3).

12. Pratter MR, Irwin RS. Transtracheal aspiration. Guidelines for safety. Chest. 1979;76(5):518-520.

13. Almeida EP. Almeida AC, Almeida FF, et al. Transtracheal Puncture:a forgotten procedure. Brazilina journal of medical and biological research. 2015;48(8):665-764. 